\title{
Evaluation of the use of tacrolimus ointment for the prevention of hypertrophic scars in experimental model ${ }^{*}$
}

\author{
Mariana Campos Souza Menezes ${ }^{1}$, Leonardo de Souza Vasconcellos², Cristiana Buzelin Nunes ${ }^{3,4,5}$, \\ Luiz Ronaldo Alberti ${ }^{1,6}$
}

DOI: http:/ / dx.doi.org/10.1590/abd1806-4841.20197490

\begin{abstract}
BACKGROUND: Tacrolimus, for its activity on modulation of collagen production and fibroblast activity, may have a role in the prevention of hypertrophic scars.

ОвлестіVEs: Evaluate macroscopic, microscopic, metabolic, laboratory effects and side effects of the use of topical tacrolimus ointment, in different concentrations, in the prevention of hypertrophic scars.

Methods: Twenty-two rabbits were submitted to the excision of 2 fragments of $1 \mathrm{~cm}$ of each ear, $4 \mathrm{~cm}$ apart, down to cartilage. The left ear of the animals was standardized as control and Vaseline applied twice a day. The right ear received tacrolimus ointment, at concentrations of $0.1 \%$ on the upper wound and $0.03 \%$ on the lower wound, also applied twice a day. Macroscopic, microscopic, laboratory criteria and the animals' weight were evaluated after 30 days of the experiment.

RESULTS: Wounds treated with tacrolimus, at concentrations of $0.1 \%$ and $0.03 \%$, when compared to control, showed a lower average degree of thickening $(\mathrm{p}=0.048$ and $\mathrm{p}<0.001$, respectively). The average of scar thickness and lymphocyte, neutrophil and eosinophil concentrations are lower in the treated wounds compared to the control $(p<0.001, p=0.022, p=0.007, p=0.044$, respectively). The mean concentration of lymphocytes is lower in wounds treated with a higher concentration of the drug $(\mathrm{p}=0.01)$.

STUdy LimitATIONS: experiment lasted only 30 days.

Conclusions: Tacrolimus at the 2 concentrations evaluated reduced the severity of inflammatory changes and positively altered the macroscopic aspect of the scar in the short term. Its use was shown to be safe, with no evidence of systemic or local adverse effects.
\end{abstract}

Keywords: Cicatrix; Cicatrix, hypertrophic; Inflammation; Keloid; Rabbits; Skin; Tacrolimus; Wound healing

\section{INTRODUCTION}

Cutaneous healing has many interdependent phases that occur dynamically and harmoniously. Factors intrinsic to the individual and also external can participate in healing and lead to an unsightly scar, whose prevention is more effective than treatment.
When the scars progress to an unsightly aspect, most of them can be classified as hypertrophic scarring or keloids. ${ }^{1}$ The word keloids comes from the Greek cheloides, meaning crab. ${ }^{2}$

Keloids and hypertrophic scars affect mainly non-Cauca-

\footnotetext{
Received on 01 August 2017.

Accepted on 31 March 2018.

* Study conducted at Instituto de Ensino e Pesquisa da Santa Casa de Belo Horizonte, Belo Horizonte (MG), Brazil

Financial support: None.

Conflict of interest: None.

Teaching and Research Center, Santa Casa de Belo Horizonte, Belo Horizonte (MG), Brazil.

Department of Complementary Propaedeutic, Faculdade de Medicina, Universidade Federal de Minas Gerais, Belo Horizonte (MG), Brazil.

Department of Anatomical Pathology, Faculdade de Medicina, Universidade Federal de Minas Gerais, Belo Horizonte (MG), Brazil.

Health and Biological Science institute, Curso de Medicina, Centro Universitário de Belo Horizonte, Belo Horizonte (MG), Brazil.

Service of Pathology, Instituto Moacyr Junqueira, Belo Horizonte (MG), Brazil.

Department of Surgery, Universidade Federal de Minas Gerais, Belo Horizonte (MG), Brazil.
}

MAILING AdDRess:

Mariana Campos Souza Menezes

E-mail: marianacamposmn@terra.com.br 
sian adults in the second and third decades of life, with no gender predilection, coming from tropical areas. The Afro-American population has a $10 \%$ incidence of keloids. ${ }^{3-4}$ Keloid pathogenesis is not yet fully understood, but it is known that there is an increased deposition of extracellular matrix, which can extend from the dermis to the subcutis. Besides, there is an inflammatory reaction and dermal fibroblasts with increased activity and fibrin hyperproliferation, reduction or absence of elastic fibers can be seen. It usually occurs due to the loss of the balance between collagen production and degradation. ${ }^{5}$

Hypertrophic scars are restricted to the area of the primary trauma and do not go beyond the scar limits. Most of the times, they are an intermediate state of the healing process, progressing to spontaneous resolution in up to six months.

Tacrolimus is a macrolide immunomodulator produced in the Tsukuba region in Japan, originated from Streptomyces tsukubaensis, discovered in $1984 .{ }^{6}$ It inhibits the phosphorylation of transcription factors, a process mediated by calcineurin, resulting in the inhibition of the synthesis of inflammatory cytokines that would be produced by T lymphocytes (IL-2, IL-3, IL4, IL-5, TNF- $\alpha$ and granulocyte stimulating factors). ${ }^{7}$ In this way, it inhibits the activation of mast cells and neutrophils and affects the function of basophils, eosinophils and Langerhans cells. ${ }^{8}$

The medication is used to prevent keloid due to its action in the activity of fibroblasts and modulation of the collagen production. An experimental study in rabbits using tacrolimus intradermally showed satisfactory results for the prevention of hypertrophic scarring. ${ }^{9}$ However, there are no studies in the literature using the medication topically, in ointment, with the same goal. The number of studies using tacrolimus for the prevention of unsightly scarring is still very little, making its use for this purpose still restricted.

The objective of this study was to evaluate the macroscopic, microscopic, metabolic, laboratory effects and possible side effects of the use of different concentrations of tacrolimus ointment for the prevention of hypertrophic scarring, using the model of rabbits' ears.

\section{METHODS}

This is an experimental study with laboratory animals, conducted according to the recommendations of the International Standards on Animal Welfare and the Código Brasileiro de Experimentação Animal (1988) and was approved on 23 May 2016 by the ethics committee of animal use under the protocol number 74/2016.10-12

Twenty-two male, white, New Zealand rabbits (Oryctolagus cuniculus), aged around two months were used. The initial weight of the animals was $2.16 \mathrm{~kg}$. The animals were identified by numbers and placed into individual cages, in an appropriate place, with controlled ventilation and lighting. They were fed with a particular commercial food and had ad libitum water throughout the period of the experiment. Their excrements were removed daily and discarded in specific containers.

All animals went through a period of approximately 48 hours of adaptation and observation of the state of health, with assessment of vital signs and clinical examination before the first surgical procedure.
On the day of the first surgical procedure, blood samples were collected through venipuncture of the auricular vein and after the death of the animals on the $30^{\text {th }}$ day of the experiment, new samples were collected through intra-cardiac puncture. The samples were processed and urea (UR), creatinine (CR), alanine transaminase (ALT), albumin (ALB) and gamma-glutamyl transferase (GGT) were dosed.

The rabbits were anesthetized in the left gluteal region with an intramuscular injection of ketamine $45 \mathrm{mg} / \mathrm{kg}$ associated to xylazine $7 \mathrm{mg} / \mathrm{kg}$. Throughout the anesthetic induction and during the surgical procedure the vital signs were checked and voluntary movements were evaluated. Two animals died during anesthetic induction.

The ventral skin of the rabbits' ears was marked with a gauge with two $1 \mathrm{~cm}$ diameter circles $4 \mathrm{~cm}$ apart in a straight line in order to avoid interaction between the wounds. Circular fragments were excised from the marking down to cartilage, including perichondrium (Figure 1).

The animals' wounds were distributed into two main groups by a draw after the surgical procedure. The surgeon did not know to which group each wound belonged whilst performing the procedure.

The left ear was standardized as control and was treated with Vaseline twice a day. The right ear of the animals was treated with tacrolimus ointment $0.1 \%$ on the upper wound and ointment $0.03 \%$ on the lower wound, also applied twice a day.

Macroscopic criteria: degree of scar thickening and local erythema.

Microscopic criteria: thickness of the normal dermis, scar length, scar thickness, and concentration of capillaries, lymphocytes, neutrophils, eosinophils, granulomas, and macrophages were evaluated on day 30 of the experiment.

Macroscopic criteria were assessed in in vivo animals by two observers, in order to reduce single observer bias. A scale to determine the degree of erythema was adopted: 0 corresponds to no erythema; 1 to subtle erythema located in some areas of the scar;

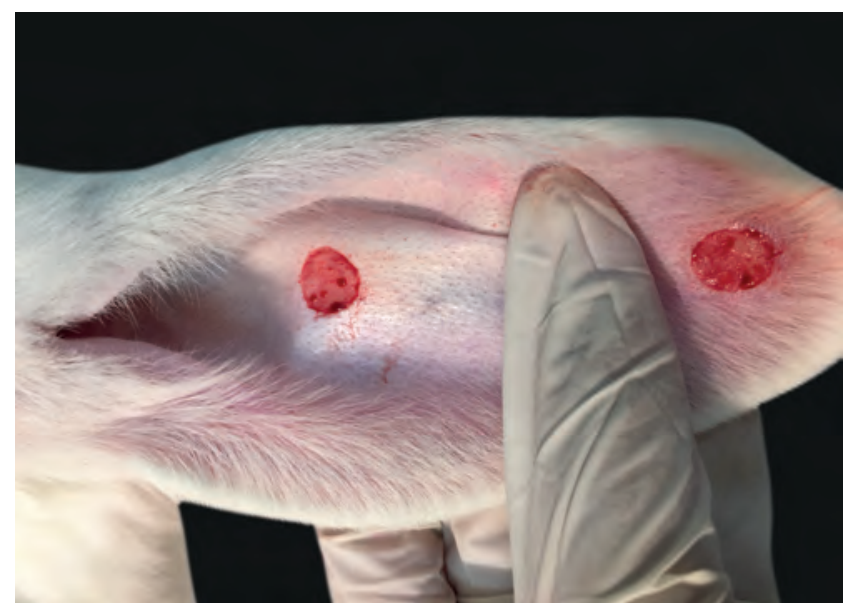

FIGURE 1: Incisions in the rabbit's ear 
and 2 to obvious erythema involving the whole scar. To standardize data regarding scar thickness, another scale was established: 0 corresponds to absence of perceptible thickening; 1 to scar with less than $1 \mathrm{~mm}$ thickening; and 2 to scar with 1 to $2 \mathrm{~mm}$ thickening. The treatment group to where each wound analyzed was part of, was not revealed to the observers.

Histological analyses were carried out by two observers concomitantly. During the analysis, the pathologists were unaware of the group of each wound. Re-epithelialization areas were analyzed under light microscopy with X40 and X100 magnification. The concentration of capillaries, lymphocytes, neutrophils, eosinophils, granulomas, and macrophages was quantified from the analysis of two circular areas under X40 magnification, each area with a diameter of $600 \mu \mathrm{m}$, in two different and random sites in the area of the scar. The concentration obtained in both areas was added in order to obtain only whole numbers.

Laboratory criteria: urea, creatinine, alanine transaminase, gamma-glutamyl transferase, albumin levels and the weight of the animals were assessed in the beginning and after the 30 days of experiment.

Throughout the statistical analysis, continuous data were tested for normality with the Kolmogorov-Smirnov test, that indicated normality present in variables and therefore, the class of parametric tests was used.

To compare the means of independent groups, Student's $\mathrm{t}$-test and for paired groups, the paired t-test were used.

In all tests, the significance level of $5 \%$ was used, therefore differences are significant considering $p<=0.05$.

\section{RESULTS}

The mean weight of the animals was higher after 30 days of the experiment when compared to the mean before surgery (Figure 2).
When compared to the respective controls, the wounds treated with tacrolimus in the concentrations of $0.1 \%$ and $0.03 \%$ had a lower degree of thickening, $\mathrm{p}=0.048$ and $\mathrm{p}<0.001$, respectively (Figures 3 to 5). The wounds treated with the higher concentration of the medication showed less local erythema than control $(p<0.001)$.

Inclusion cysts in three wounds, micro-abscesses in two wounds, crust formation in three wounds and dermal hemorrhage in one wound were the microscopic changes described in the left ear, i.e., the control ear that was only treated with the vehicle (Figure 6).

The mean creatinine and alanine transaminase levels was higher after 30 days of the experiment when compared to before the surgery $(\mathrm{p}<0.001)$. The mean levels of gamma-glutamyl transferase and albumin were lower after the intervention when compared to before the procedure $(\mathrm{p}<0.001)$ (Table 1$)$

The mean scar thickness and concentration of lymphocytes, neutrophils and eosinophils was lower in the wounds treated with the medication when compared to control $(\mathrm{p}<0.001, \mathrm{p}=0.022$, $\mathrm{p}=0.007, \mathrm{p}=0.044$, respectively) (Table 2).

When comparing the upper wounds, between tacrolimus $0.1 \%$ and control, significant differences were observed in the following: concentration of lymphocytes, neutrophils, granulomas, and macrophages, with lower mean concentrations in the wounds treated than in controls $(\mathrm{p}=0.013 ; 0.024 ; 0.023 ; 0.027)$ and scar thickness, also with a lower mean in the treated group $(p=0.012)$. Still comparing the upper wounds, for thickness of the normal dermis and concentration of capillaries, the mean values were higher for treated wounds ( $\mathrm{p}=0.012$ and $\mathrm{p}<0.001$, respectively) (Table 3 ).

The lower wounds treated with tacrolimus $0.03 \%$ showed a mean scar thickness lower than control wounds $(p=0.022)$. The mean capillary concentration and mean thickness of the normal dermis were higher in wounds treated with tacrolimus $0.1 \%$ that in those treated with tacrolimus $0.03 \%(p=0.026 ; p<0.001$, respective-

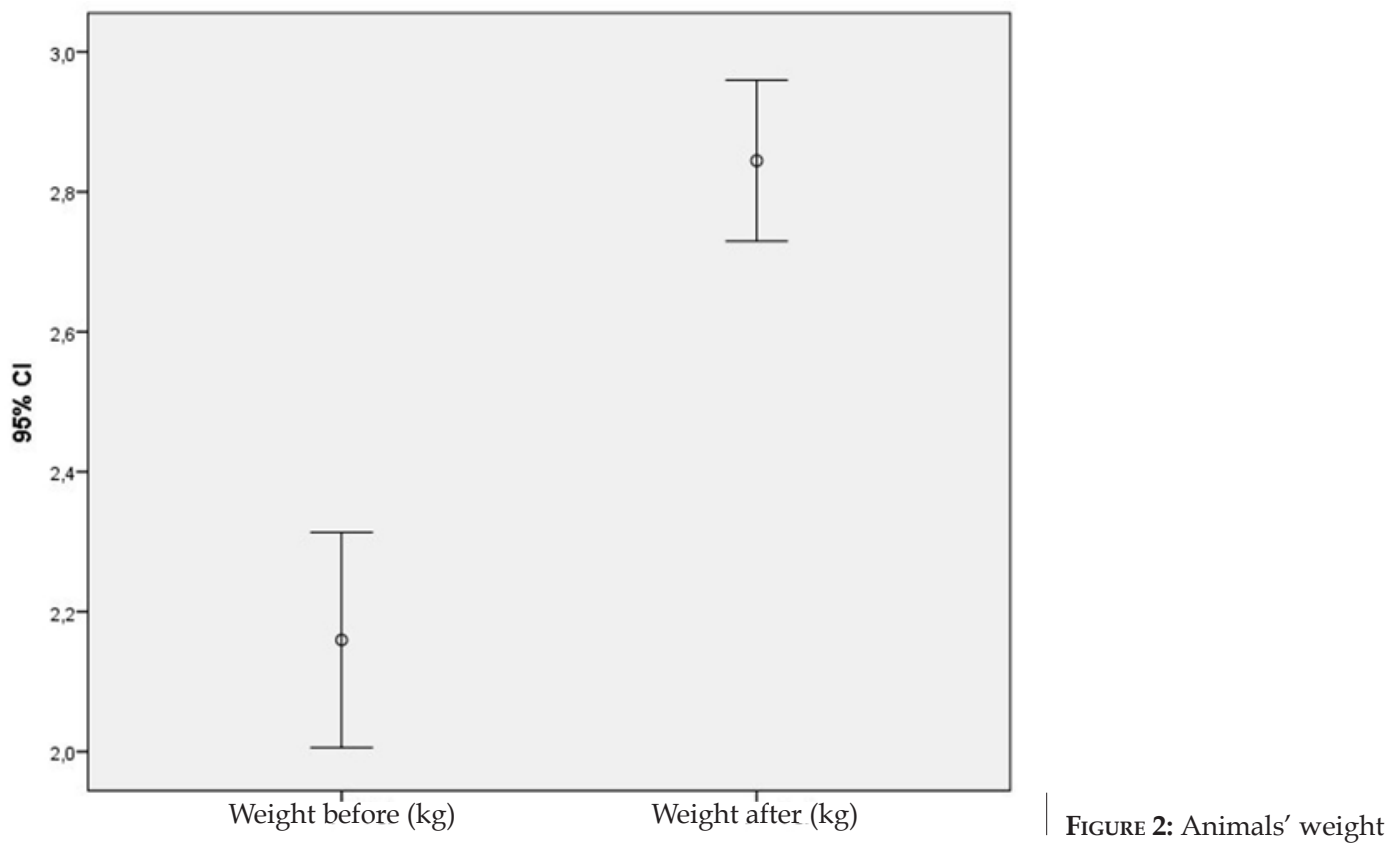


ly). The mean concentration of lymphocytes was lower in wounds treated with the higher concentration of the medication $(\mathrm{p}=0.01)$.

\section{DISCUSSION}

Superficial wounds, i.e., excoriations that only affect the epidermis, rarely progress to a keloid or hypertrophic scar. Unsight-

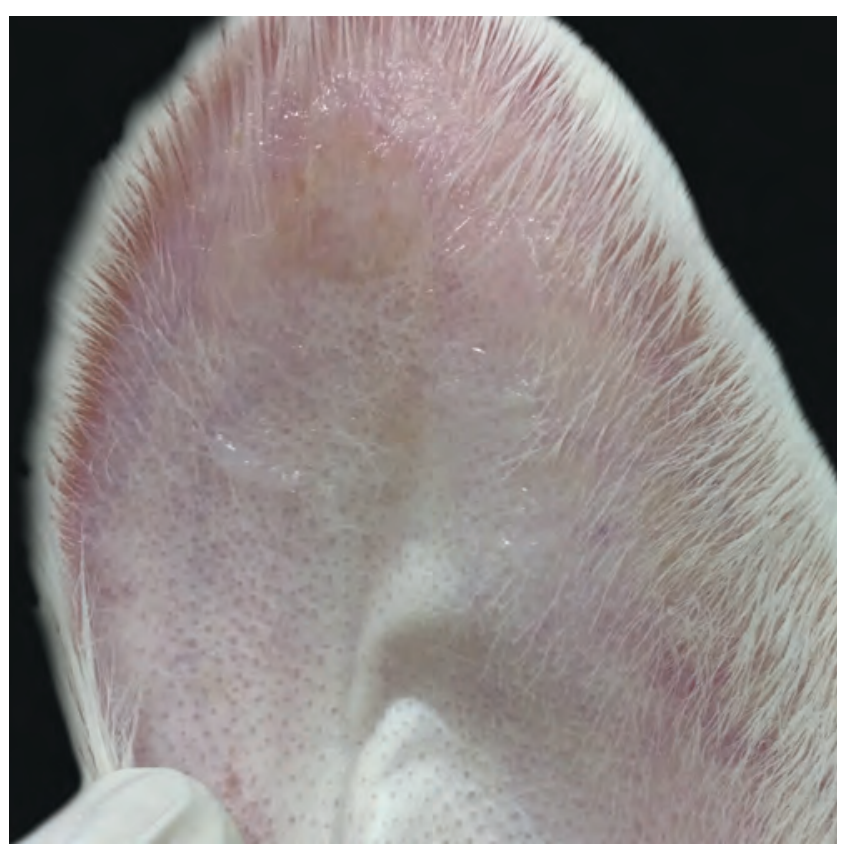

Figure 3: Wound macroscopy 30 days after the experiment. Wound treated with tacrolimus $0.1 \%$ : reduced thickness and less erythema than in controls

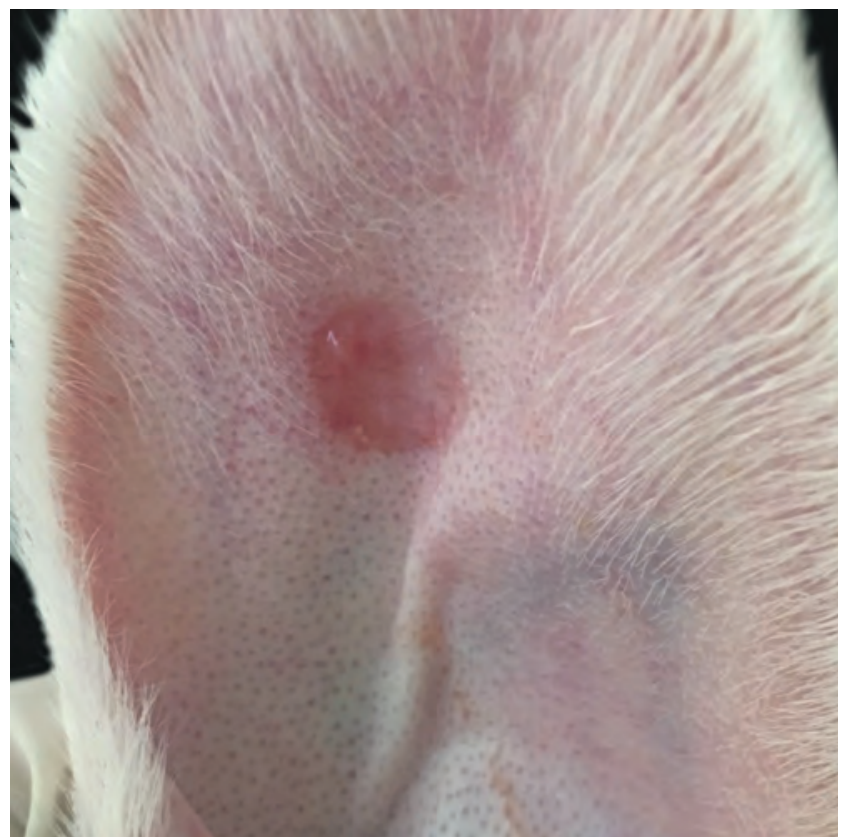

FIGURE 4: Wound macroscopy 30 days after the experiment. Wound treated with tacrolimus $0.03 \%$ : reduced thickness compared to controls ly scars usually become visible macroscopically around one to three months after the triggering trauma. When these data are added, the most obvious histological changes in the reticular dermis, such as newly formed vessels, increased concentration of fibroblasts and collagen deposition point to the fact that unsightly scars, keloids and hypertrophic scars arise from a chronic inflammatory process in the reticular dermis that begins at the time of the injury and continues for months. ${ }^{13}$

The choice of the follow-up period of 30 days for the wounds after the initial injury was established based in reference studies and the availability of the researchers, but a study with a 90 days follow-up period could offer complementary results.

Tacrolimus is still not found in the standardized medication list for the topical treatment of unsightly scars, because there are few studies regarding this use of the medication. ${ }^{14}$

The model of hypertrophic scars in rabbits' ears was suggested in 2007 by the Mustoe protocol. It demonstrated the dorsum

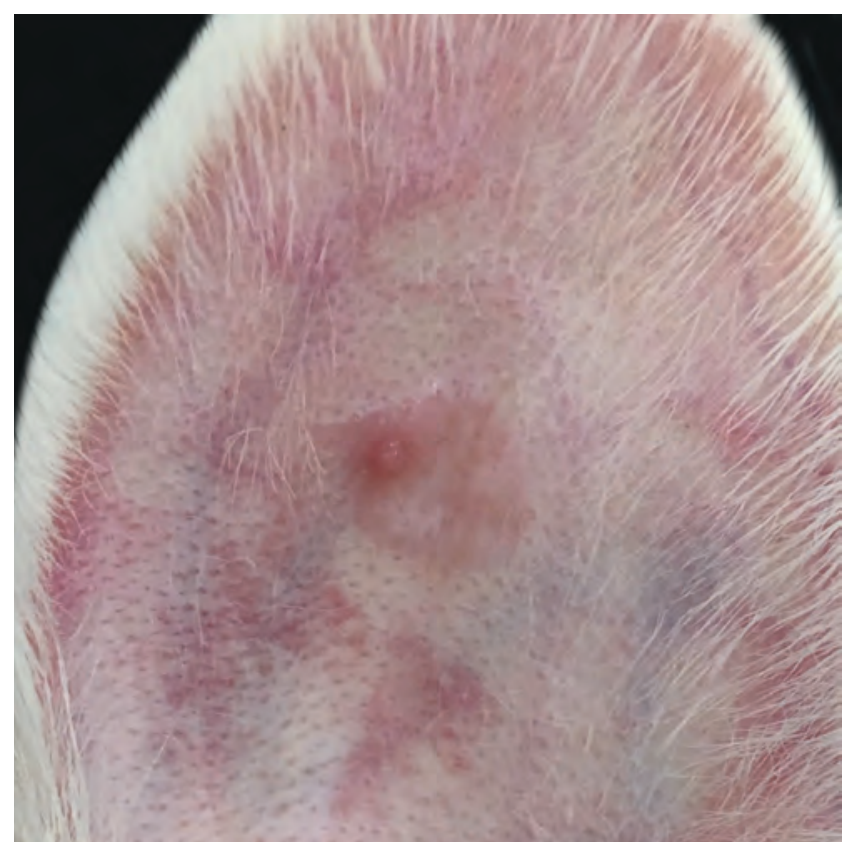

FIGURE 5: Wound macroscopy 30 days after the experiment. Thicker control wound and with more erythema

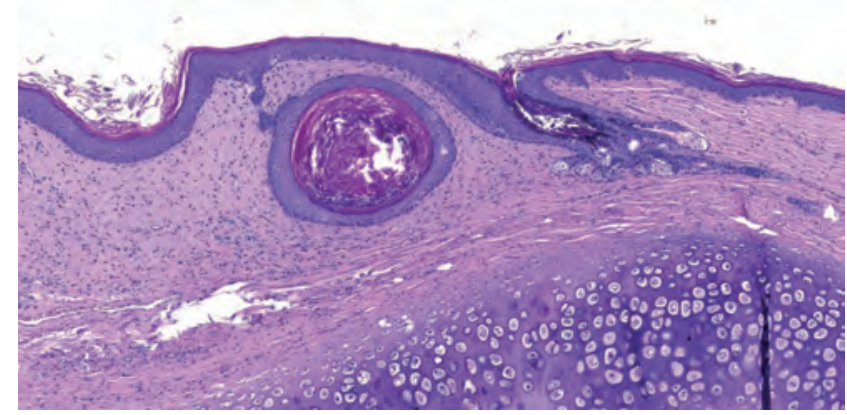

Figure 6: Wound microscopy from a control ear. Inclusion cyst. (Hematoxylin \& eosin, x50) 
of rabbits' ears as the best site for the formation and reproduction of hypertrophic scarring, which could be evaluated and studied over a period of 30 days. ${ }^{15}$ This model in rabbits' ears was reproduced in many subsequent studies with many medications of local use, including studies using tacrolimus, ${ }^{9}$ but none of them used tacrolimus ointment.

The choice of the concentrations used, the administration route and tacrolimus vehicle, $0.1 \%$ and $0.03 \%$ topical ointment, was based on the availability and ease of access in the market and previous studies with other administration routes and concentrations and positive results, ${ }^{9}$ and on reports of improvement of scars in patients using the medication in the concentration and route tested for the treatment of atopic dermatitis. ${ }^{16,17}$ Another reason to use the medication as an ointment was the existence of a previous study that tested it as the single intradermal injection and raised the question whether the medication would be effective as a cream or an

\begin{tabular}{|c|c|c|c|c|c|c|c|}
\hline Variable & $\mathbf{N}$ & Mean & Standard Deviation & Mean Difference & $95 \%$ & CI & $P$ Value \\
\hline Urea - before (mg/dL) & $15^{*}$ & 24.13 & 5.18 & 2.58 & -0.20 & 5.36 & 0.067 \\
\hline Urea - after (mg/dL) & $15^{*}$ & 21.55 & 5.08 & & & & \\
\hline Creatinine - before $(\mathrm{mg} / \mathrm{dL})$ & 20 & 0.45 & 0.13 & -0.26 & -0.35 & -0.18 & $<0.001$ \\
\hline Creatinine - after (mg/dL) & 20 & 0.72 & 0.15 & & & & \\
\hline ALT - before (U/L) & 20 & 24.44 & 11.69 & -34.04 & -44.13 & -23.95 & $<0.001$ \\
\hline ALT - after (U/L) & 20 & 58.48 & 23.38 & & & & \\
\hline GGT - before (U/L) & $17^{*}$ & 34.39 & 14.64 & 21.91 & 13.02 & 30.80 & $<0.001$ \\
\hline GGT - after (U/L) & $17^{*}$ & 12.49 & 5.10 & & & & \\
\hline ALB - before (g/dL) & 20 & 4.30 & 0.80 & 1.23 & 0.82 & 1.65 & $<0.001$ \\
\hline ALB - after (g/dL) & 20 & 3.07 & 0.54 & & & & \\
\hline
\end{tabular}

* $\mathrm{N}$ values lower than 20 due to hemolysis of some samples

ALT: Alanine transaminase

GGT: Gamma glutamyl transferase

ALB: Albumin

TABLE 2: Microscopic evaluation after the 30th day of experiment: wounds on the right ear compared to the left ear, regardless of the concentration of the medication

\begin{tabular}{|c|c|c|c|c|c|c|c|}
\hline Comparisons DXE & $\mathbf{N}$ & Mean & Standard Deviation & Mean Difference & 95\% CI & $P$ Value & $P$ Value \\
\hline Thickness of normal dermis $(\mu \mathrm{m}) \mathrm{D}$ & 40 & 377.52 & 64.56 & \multirow{2}{*}{1.67} & \multirow{2}{*}{-30.15} & \multirow{2}{*}{33.49} & \multirow{2}{*}{0.916} \\
\hline Thickness of normal dermis $(\mu \mathrm{m}) \mathrm{E}$ & 40 & 375.85 & 107.82 & & & & \\
\hline Scar length $(\mu \mathrm{m}) \mathrm{D}$ & 40 & 9252.23 & 1519.77 & \multirow{2}{*}{275.44} & \multirow{2}{*}{-360.41} & \multirow{2}{*}{911.29} & \multirow{2}{*}{0.386} \\
\hline Scar length $(\mu \mathrm{m}) \mathrm{E}$ & 40 & 8976.79 & 1474.14 & & & & \\
\hline Scar thickness $(\mu \mathrm{m}) \mathrm{D}$ & 40 & 656.59 & 226.94 & \multirow{2}{*}{-273.07} & \multirow{2}{*}{-419.09} & \multirow{2}{*}{-127.05} & \multirow{2}{*}{0.001} \\
\hline Scar thickness $(\mu \mathrm{m}) \mathrm{E}$ & 40 & 929.66 & 505.25 & & & & \\
\hline Capillary concentration D & 40 & 32.05 & 8.34 & \multirow{2}{*}{2.60} & \multirow{2}{*}{-1.63} & \multirow{2}{*}{6.83} & \multirow{2}{*}{0.221} \\
\hline Capillary concentration $\mathrm{E}$ & 40 & 29.45 & 9.94 & & & & \\
\hline Lymphocyte concentration D & 40 & 61.78 & 37.65 & \multirow{2}{*}{-17.70} & \multirow{2}{*}{-32.69} & \multirow{2}{*}{-2.71} & \multirow{2}{*}{0.022} \\
\hline Lymphocyte concentration E & 40 & 79.48 & 37.77 & & & & \\
\hline Presence of neutrophils D & 40 & 4.00 & 5.68 & \multirow{2}{*}{-4.93} & \multirow{2}{*}{-8.41} & \multirow{2}{*}{-1.44} & \multirow{2}{*}{0.007} \\
\hline Presence of neutrophils E & 40 & 8.93 & 11.39 & & & & \\
\hline Presence of eosinophils D & 40 & 4.15 & 11.14 & \multirow{2}{*}{-49.45} & \multirow{2}{*}{-97.44} & \multirow{2}{*}{-1.46} & \multirow{2}{*}{0.044} \\
\hline Presence of eosinophils E & 40 & 53.60 & 149.27 & & & & \\
\hline Presence of granulomas D & 40 & 0.55 & 0.90 & \multirow{2}{*}{-0.13} & \multirow{2}{*}{-0.55} & \multirow{2}{*}{0.30} & \multirow{2}{*}{0.560} \\
\hline Presence of granulomas E & 40 & 0.68 & 1.00 & & & & \\
\hline Presence of macrophages D & 40 & 22.13 & 35.58 & \multirow{2}{*}{-14.30} & \multirow{2}{*}{-34.23} & \multirow{2}{*}{5.63} & \multirow{2}{*}{0.155} \\
\hline Presence of macrophages E & 40 & 36.43 & 50.69 & & & & \\
\hline
\end{tabular}

D: Tacrolimus group

E: Control group 


\begin{tabular}{|c|c|c|c|c|c|c|c|}
\hline Comparisons DS x ES & $\mathbf{N}$ & Mean & Standard Deviation & Mean Difference & $95 \%$ & CI & $P$ Value \\
\hline Thickness of normal dermis $(\mu \mathrm{m})$ DS & 20 & 336.11 & 53.13 & \multirow{2}{*}{46.10} & \multirow{2}{*}{11.31} & \multirow{2}{*}{80.90} & \multirow{2}{*}{0.012} \\
\hline Thickness of normal dermis $(\mu \mathrm{m})$ ES & 20 & 290.01 & 42.44 & & & & \\
\hline Scar length $(\mu \mathrm{m}) \mathrm{DS}$ & 20 & 9298.88 & 1531.48 & \multirow{2}{*}{103.75} & \multirow{2}{*}{-592.70} & \multirow{2}{*}{800.20} & \multirow{2}{*}{0.759} \\
\hline Scar length $(\mu \mathrm{m}) \mathrm{ES}$ & 20 & 9195.13 & 1187.50 & & & & \\
\hline Scar thickness $(\mu \mathrm{m}) \mathrm{DS}$ & 20 & 656.05 & 246.52 & \multirow{2}{*}{-305.78} & \multirow{2}{*}{-535.07} & \multirow{2}{*}{-76.50} & \multirow{2}{*}{0.012} \\
\hline Scar thickness $(\mu \mathrm{m})$ ES & 20 & 961.84 & 479.01 & & & & \\
\hline Capillary concentration DS & 20 & 34.95 & 6.60 & \multirow{2}{*}{7.20} & \multirow{2}{*}{3.26} & \multirow{2}{*}{11.14} & \multirow{2}{*}{0.001} \\
\hline Capillary concentration ES & 20 & 27.75 & 7.97 & & & & \\
\hline Lymphocyte concentration DS & 20 & 46.75 & 32.90 & \multirow{2}{*}{-22.90} & \multirow{2}{*}{-40.31} & \multirow{2}{*}{-5.49} & \multirow{2}{*}{0.013} \\
\hline Lymphocyte concentration ES & 20 & 69.65 & 36.67 & & & & \\
\hline Presence of neutrophils DS & 20 & 2.35 & 5.62 & \multirow{2}{*}{-4.85} & \multirow{2}{*}{-8.99} & \multirow{2}{*}{-0.71} & \multirow{2}{*}{0.024} \\
\hline Presence of neutrophils ES & 20 & 7.20 & 11.01 & & & & \\
\hline Presence of eosinophils DS & 20 & 3.85 & 13.10 & \multirow{2}{*}{-50.80} & \multirow{2}{*}{-121.04} & \multirow{2}{*}{19.44} & \multirow{2}{*}{0.147} \\
\hline Presence of eosinophils ES & 20 & 54.65 & 149.29 & & & & \\
\hline Presence of granulomas DS & 20 & 0.35 & 0.67 & \multirow{2}{*}{-0.70} & \multirow{2}{*}{-1.29} & \multirow{2}{*}{-0.11} & \multirow{2}{*}{0.023} \\
\hline Presence of granulomas ES & 20 & 1.05 & 1.05 & & & & \\
\hline Presence of macrophages DS & 20 & 18.45 & 38.39 & \multirow{2}{*}{-28.20} & \multirow{2}{*}{-52.84} & \multirow{2}{*}{-3.56} & \multirow{2}{*}{0.027} \\
\hline Presence of macrophages ES & 20 & 46.65 & 36.70 & & & & \\
\hline
\end{tabular}

DS: Tacrolimus group $0.1 \%$

ES: Control group

ointment, since it would take longer to achieve therapeutic concentrations in the dermis, where the healing process takes place. ${ }^{9}$

In the literature, the association of tacrolimus to progressive nephropathy when present systemically is well-documented. ${ }^{18}$ Serum creatinine only would not be the best indicator of renal function. An association of this marker to creatinine clearance would be a more accurate indicator. ${ }^{19,20}$ Studies in mice demonstrate that animals with chronic kidney disease are affected with more adverse events from tacrolimus related to nephrotoxicity. These mice had higher levels of serum creatinine, lower levels of creatinine clearance and more weight-loss. ${ }^{21}$

The normal levels of serum creatinine in rabbits range between 0.51 to $1.53 \mathrm{mg} / \mathrm{dL}$ and such levels can vary according to the seasons, according to Spinelli MO et al..$^{22,23}$

Despite the differences in the level of serum creatinine before and after the experiment, the mean of the values is below the higher reference limit, indicating lack of significant impairment in the rabbits' renal function, what can be corroborated by the weight gain seen throughout the experiment, ruling out systemic adverse events from tacrolimus.

Biochemical tests to evaluate liver function can be divided into indicative of hepatocellular injury, which are the ones that evaluate aminotransferases, and indicative of cholestasis, based in alkaline phosphatase and gamma-glutamyl transferase levels. ${ }^{24}$

The mean serum alanine transaminase in animals after the intervention was higher than before the intervention, with a twofold increase of the initial level, suggesting that this variation might not be due to pathological causes, but to environmental causes. According to Abfadel et al, ${ }^{25}$ increases between 15 and 100 times of the liver aminotransferases could be observed in the acute phase of hepatitis; whereas in hepatic steatosis the serum levels tend to be mildly elevated.

Alanine transaminase is also found in muscle and heart cells and is not as specific for liver disease as aspartate transaminase. Gamma-glutamyl transferase is present in the cells of the bile ducts, heart, pancreas and can be increased by drugs such as corticosteroids and anticonvulsants. ${ }^{26,24}$

The reduction in the mean serum levels of gamma-glutamyl transferase during the experiment is in accordance with the suggestion of possible environmental causes for the increase in alanine transaminase. Inverse changes of such liver markers would not be justified if there was any pathological involvement of the animals' liver. For rabbits, gamma-glutamyl transferase reference levels are between 2IU and 15IU.22 At the end of the experiment, the animals showed GGT levels within the normal range. Unfortunately, some samples were hemolyzed and a $\mathrm{N}$ of less than 20 was adopted to evaluate GGT.

Despite the reduction of the mean values of serum albumin, albumin concentrations remained within the parameters established by Kaneko ${ }^{27}$ in 1989, once again demonstrating the lack of pathological liver involvement in the animals studied.

Regarding the macroscopic analysis of the scars, a lower degree of scar thickening in the wounds treated with tacrolimus in both concentrations, $0.1 \%$ and $003 \%$, was observed comparing to 
the corresponding control. Wounds treated with the higher concentration of the medication had a lower degree of scar thickness when comparing to the wounds treated with the lower concentration of the medication. Such results support the literature since according to Berman et $a l,{ }^{16,17}$ children treated with tacrolimus ointment for atopic dermatitis demonstrated a reduction in their scars. Dean et $a l^{28}$ showed that in renal transplant patients on tacrolimus, the complications of their scars are lower, corroborating the hypothesis of the positive effect of the drug on the treatment of unsightly scars. Currently, tacrolimus has been used to prevent re-stenosis in patients submitted to placement of stents, what was treated for many years in the past with brachytherapy, a procedure also used to treat keloid scars. ${ }^{29,30}$ By analogy, we can infer that if brachytherapy was beneficial for the treatment of hypertrophic scars, tacrolimus might also be. Gisquet et al. ${ }^{9}$ demonstrated the beneficial effect of tacrolimus when used intradermally in a single dose for the prevention of hypertrophic scarring in their study and showed that such effect was dose-dependent. They used three concentrations of the medication: the lower concentration had poorer results while the higher concentration proved to be the most effective.

When applied topically, the following are considered adverse events of tacrolimus: atrophy, depigmentation, telangiectasias, infection and necrosis, besides weight loss. ${ }^{9}$ None of these events were seen in any of the wounds analyzed. The fact that less erythema was seen in wounds exposed to the higher concentration of the medication and the constant weight gain of the animals over the 30 days confirms the lack of adverse events to the medication in the experimental model used.

Healing is divided into two phases. Prostaglandins such as TGF- $\beta$ are released in the wound and stimulate leukocyte migration into the area in the second phase of this process, the inflammatory phase. ${ }^{31}$ Neutrophils are the first and one of the main inflammatory cells to reach the scar in this phase and have an active role in the activity of fibroblasts and keratinocytes. Many studies demonstrated the activity of TGF- $\beta$ as a keloid inductor and see in this marker a target to be inhibited in order to reduce the formation of unsightly scars. ${ }^{32-34}$ According to Bekersky et al., ${ }^{35}$ tacrolimus inhibits TGF- $\beta$, what would potentiate its beneficial activity in the scar evolution. Thus, since the drug studied inhibits TGF- $\beta$, a reduction in the migration of leukocytes, their concentration in the treated wounds and, consequently, reduction in the genesis of hypertrophic scars is expected, what can be confirmed in the present study by the reduced thickness of the scars treated with the medication.

Macrophages are attracted to the scar during the inflammation phase by the activity of TGF- $\beta$. With TGF- $\beta$ being inhibited by the activity of the medication in healing, it is expected that the mean concentration of macrophages in these treated wounds be lower. ${ }^{36}$

Granulomas can occur as a response to a foreign body or to external microorganisms. The fact that there was less formation of granulomas in the wounds treated with tacrolimus confirms the statement that there was no secondary infection present in the treated wounds, this being one of the adverse events of the drug reported in the literature. ${ }^{9}$

Capillary formation occurs during the third phase of healing, angiogenesis. This phase is essential for tissue regeneration, particularly in the proliferative phase, but many studies have shown that excessive angiogenesis is related to fibrotic scars. ${ }^{37,38} \mathrm{~A}$ study conducted by Kwak et al., ${ }^{39}$ using the same model of rabbits' ears, showed that preventing excessive angiogenesis is an effective measure for the prevention of hypertrophic scarring, but should not be the only one adopted. The sum of the highest mean concentration of capillaries obtained in the wounds treated with tacrolimus $0.1 \%$ and the reduction of the micro and macroscopic thickness of these scars leads to the hypothesis that the angiogenesis in these wounds was not excessive but physiological, and that angiogenesis control cannot be considered one of the ways the medication acts in regards to the prevention of hypertrophic scarring.

The wounds treated with tacrolimus $0.1 \%$ had a higher mean concentration of capillaries and a lower mean concentration of lymphocytes when compared to those treated with tacrolimus $0.03 \%$, with no significant difference in the thickness of the scar, what suggests more control of the inflammatory phase, with lower concentration of leukocytes in the wound that in fact did not significantly change the evolution of the scar. Once again, we raise the hypothesis that the drug does not act in angiogenesis.

In $32.5 \%$ of the wounds not treated with the medication, cartilage destruction with areas of newly formed and hypertrophied cartilage were observed, what did not occur in any of the treated wounds. In 2011, Gisquet H et al., ${ }^{9}$ in their experiment with the same experimental model of the present study, demonstrated that removal of the perichondrium would extend the cicatricial inflammatory process from the dermis to the cartilage, what could justify these changes in the cartilage and contribute to the formation of the scar, changing also its degree of thickness. Other studies using the same model of rabbits' ears did not mention similar changes. Thus, the medication used probably acted both in the dermis and in the cartilage area, reducing the inflammatory process and improving the scar, since the depth of the incision was the same for all studied groups.

Other complications such as hemorrhage in the dermis, microabscesses and inclusion cysts were seen in the wounds from non-treated ears, what reinforces the hypothesis that tacrolimus acts reducing the inflammatory activity in the scar and also the absence of local adverse events with the medication for the prevention of unsightly scars.

\section{CONCLUSION}

Tacrolimus decreased the severity of the inflammatory changes in microscopy, besides positively changing the macroscopic aspect of the scars in the short-term, yielding flatter and more aesthetic scars. No striking metabolic or laboratory abnormalities were seen. Its use proved to be safe, with no evidence of systemic or local side effects.

Tacrolimus in the concentration of $0.1 \%$ was more effective for the control of inflammation than the concentration of $0.03 \%$, but there was no significant microscopic or macroscopic difference in the thickness of the scar.

Both concentrations of the medication proved to be equally safe and effective for the prevention of hypertrophic scarring with the model used. $\square$ 


\section{REFERENCES}

1. Mendonça CM, Ferreira AS, Barbieri CH, Thomazine JA, Mazzer N. Efeitos do ultrasom pulsado de baixa intensidade sobre a cicatrização por segunda intenção de lesões cutâneas totais em ratos. Acta Ortop Bras. 2006;14:152-57.

2. Jiang Z, Yu Q, Xia L, Zhang Y, Wang X, Wu X, et al. Growth Differentiation Factor-9 Promotes Fibroblast Proliferation and Migration in Keloids through the Smad2/3 Pathway. Cell Physiol Biochem. 2016;40:207-18

3. Bailey JN, Waite AE, Clayton WJ, Rustin MH. Application of topical mitomycin C to the base of shave-removed keloid scars to prevent their recurrence. Br J Dermatol. 2007;156:682-6.

4. Wilson AM. Eradication of keloids: surgical excision followed by a single injection of intralesional 5-fluorouracil and botulinum toxin. Can J Plast Surg. 2013;21:87-91.

5. Gauglitz GG, Korting HC, Pavicic T, Ruzicka T, Jeschke MG. Hypertrophic scarring and keloids: pathomechanisms and current and emerging treatment strategies. Mol Med. 2011:17:113-25.

6. Fung JJ. Tacrolimus and transplantation: a decade in review. Transplantation. 2004:77(Suppl):S41-3.

7. Thomson AW, Bonham CA, Zeevi A. Mode of action of tacrolimus (FK506): molecular and cellular mechanisms. Ther Drug Monit. 1995;17:584-91.

8. Salgado PC, Genvigir FD, Felipe CR, Tedesco-Silva H Jr, Medina-Pestana JO, Doi SQ, et al. Association of the PPP3CA c.249G. A variant with clinical outcomes of tacrolimus-based therapy in kidney transplant recipients. Pharmgenomics Pers Med. 2017;10:101-106.

9. Gisquet H, Liu H, Blondel WC, Leroux A, Latarche C, Merlin JL, et al. Intradermal tacrolimus prevent scar hypertrophy in a rabbit ear model: a clinical, histological and spectroscopical analysis. Skin Res Technol. 2011;17:160-6.

10. Fonseca NM, Goldenberg S, Gomes PO, Lima CAP. Anestesia em coelhos. Acta Cir Bras. 1996:11:82-104.

11. Petroianu, A. Pesquisa experimental. In: Petroianu A, editor. Ética, Moral e Deontologia Médicas. Rio de Janeiro: Guanabara Koogan; 2000. p. 185-190.

12. Hoff C. Immoral and moral uses of animals. N Engl J Med. 1980;302:115-8.

13. Ogawa R. Keloid and Hypertrophic Scars Are the Result of Chronic Inflammation in the Reticular Dermis. Int J Mol Sci. 2017;18:606.

14. Khorshid FA. Comparative study of keloid formation in humans and laboratory animals. Med Sci Monit. 2005;11:212-9.

15. Kloeters 0, Tandara A, Mustoe TA. Hypertrophic scar model in the rabbit ear: a reproducible model for studying scar tissue behavior with new observations on silicone gel sheeting for scar reduction. Wound Repair Regen. 2008;16:582. Wound Repair Regen. 2007;(Suppl 1):S40-5.

16. Berman B, Villa AM, Ramirez CC.. Novel opportunities in the treatment and prevention of scarring. J Cutan Med Surg. 2004;(Suppl 3):S32-6.

17. Berman B, Viera MH, Amini S, Huo R, Jones IS.. Prevention and management of hypertrophic scars and keloids after burns in children. J Craniofac Surg. 2008:19:989-1006

18. Naesens M, Kuypers DR, Sarwal M. Calcineurin inhibitor nephrotoxicity. Clin J Am Soc Nephrol. 2009;4:481-508

19. Fernandes I, Zhang Y, Qi Y, Wang ME, Podder H, Lisik W, et al. Impact of reduced nephron mass on cyclosporine-and/or sirolimus-induced nephrotoxicity. Transplantation. 2009;88:1323-31.
20. Griffin KA, Picken M, Bidani AK. Method of renal mass reduction is a critical modulator of subsequent hypertension and glomerular injury. J Am Soc Nephrol. 1994:4:2023-31.

21. Fernandes MB, Caldas HC, Toloni LD, Baptista MA, Fernandes IM, Abbud-Filho M. Supplementation With Omega-3 Polyunsaturated Fatty Acids and Experimental Tacrolimus-Induced Nephrotoxicity. Exp Clin Transplant. 2014;12:522-7.

22. Emanuelli MP, Lopes STA, Maciel RM, Garmatz BC, Tavares MO. Concentração sérica de fosfatase alcalina, gama-glutamil transferase, uréia e creatinina em coelhos. Ciên Anim Bras. 2008;9:251-5.

23. Spinelli MO, Cruz RJ, Godoy CMSC, Motta MC, Damy SB. Estudo da variação sazonal dos parâmetros bioquímicos de roedores e lagomorfos do Biotério da Faculdade de Medicina, Universidade de São Paulo, São Paulo, Brasil. Rev Bras Med Vet. 2014;36:219-25.

24. Dial SM. Clinicopathologic evaluation of the liver. Vet Clin North Am Small Anim Pract. 1995;25:257-73.

25. Abifadel $M$, Varret $M$, Rabès JP, Allard $D$, Ouguerram $K$, Devillers $M$, et al Mutations in PCSK9 cause autosomal dominant hypercholesterolemia. Nat Genet. 2003:34:154-6.

26. Steven LS, Scott MS. Fundamentals of veterinary clinical pathology. 2nd ed. lowa: Wiley-Blackwell; 2008.

27. Kaneko JJ. Clinical Biochemistry of Domestic Animals. 4th ed. San Diego: Academic Press; 1989

28. Dean PG, Lund WJ, Larson TS, Prieto M, Nyberg SL, Ishitani MB, at al. Wound healing complications after kidney transplantation: a prospective, randomized comparison of sirolimus and tacrolimus. Transplantation. 2004;77:1555-61.

29. Butt M, Connolly D, Lip GY. Drug-eluting stents: a comprehensive ap-praisal. Future Cardiol. 2009:5:141-57.

30. Sabate M. Secondary revascularisation following intracoronary bra-chytherapy. Eurolntervention. 2009;5(D):121-126. Eurolntervention. 2009;5 (Suppl D):D121-6.

31. Clark RAF, editor. The Molecular and Cellular Biology of Wound Repair. New York: Springer; 1996, p. 3-50.

32. Kryger ZB, Sisco M, Roy NK, Lu L, Rosenberg D, Mustoe TA. Temporal expression of the transforming growth factor-Beta pathway in the rabbit ear model of wound healing and scarring. J Am Coll Surg. 2007;205:78-88.

33. Liu W, Wang DR, Cao YL.. TGF-beta: a fibrotic factor in wound scarring and a potential target for anti-scar- ring gene therapy. Curr Gene Ther. 2004;4:123-36.

34. Lu L, Saulis AS, Liu WR, Roy NK, Chao JD, Ledbetter S, et al. The temporal effects of anti-TGF- beta 1, 2, and 3 monoclonal anti- body on wound healing and hypertrophic scar formation. J Am Coll Surg. 2005;201:391-7.

35. Bekersky I, Lilja H, Lawrence I.. Tacrolimus pharmacology and non- clinical studies: from FK506 to pro- topic. Semin Cutan Med Surg. 2001 Dec;20:226-32.

36. Nurden AT, Nurden P, Sanchez M, Andia I, Anitua E. Platelets and wound healing. Front Biosci. 2008;13:3532-48.

37. Kalluri R, Sukhatme VP. Fibrosis and angiogenesis. Curr Opin Nephrol Hypertens 2000;9:413-8.

38. Wynn TA. Common and unique mechanisms regulate fibrosis in various fibroproliferative diseases. J Clin Invest. 2007;117:524-9.

39. Kwak DH, Bae TH, Kim WS, Kim HK. Anti-Vascular Endothelial Growth Factor (Bevacizumab) Therapy Reduces Hypertrophic Scar Formation in a Rabbit Ear Wounding Model. Arch Plast Surg. 2016;43:491-497.

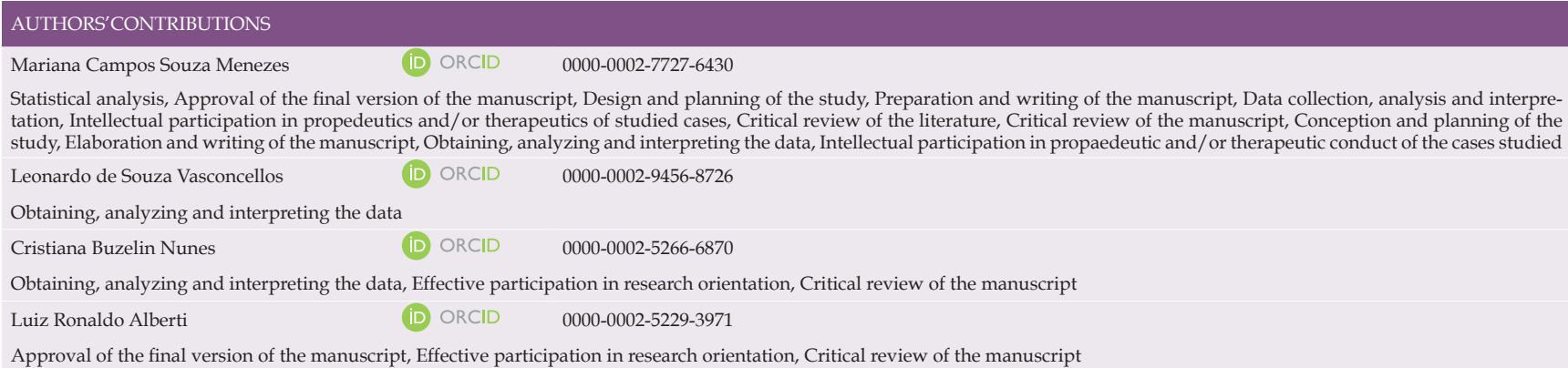

How to cite this article: Menezes MCS, Vasconcellos LS, Nunes CB, Alberti LR. Evaluation of the use of tacrolimus ointment for the prevention of hypertrophic scars in experimental model. An Bras Dermatol. 2017;94(2):164-71. 